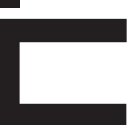

\#舟雨

$\mathbb{E}(\mathbb{E}(\mathbb{E}$

CIENTÍFICAS

EXATAS E TECNOLÓGICAS

ISSN IMPRESSO - 2359-4934

E-ISSN - 2359-4942

\title{
GESTÃO AMBIENTAL ISO 14001 NAS INDÚSTRIAS SUCROALCOOLEIRAS EM SERGIPE
}

Izaclaudia Santana da Cruz ${ }^{1}$

Roberto Rodrigues de Souza ${ }^{3}$
Isabel Cristina Barreto Andrade 2

Gregório Guirado Faccioli ${ }^{4}$

\section{RESUMO}

A atividade sucroalcooleira é impactante ao meio ambiente, seja pelo alto consumo de recursos naturais ou pela geração de resíduos, por isso este setor necessita adotar iniciativas para minimizar esses impactos. Para incentivar essas atitudes criaram-se as normas de gestão ambiental que têm como intuito o estabelecimento de diretrizes para uma gestão eficaz das atividades econômicas, a exemplo da norma certificadora ISO 14001. Diante disso, o trabalho objetivou pesquisar sobre a importância da implantação do Sistema de Gestão Ambiental ISO 14001 nas indústrias sucroalcooleiras sergipanas e propor um plano de gestão dos resíduos. A metodologia utilizada caracterizou-se como descritiva e exploratória, através de pesquisa de campo e entrevista. A implantação do plano de gestão proposto nessas indústrias permitirá o manejo adequado dos resíduos, contribuindo para a preservação ambiental.

\section{PALAVRAS-CHAVE}

Agroindústrias. Gestão Ambiental. ISO 14001. 


\section{ABSTRACT}

The sugar and ethanol activity is impacting the environment, either by high consumption of natural resources and the generation of waste, so this sector needs to adopt initiatives to minimize these impacts. To encourage these attitudes have set up environmental management standards which have as their aim the establishment of guidelines for the effective management of economic activities, such as the ISO 14001 certification Thus, the study aimed to research the importance of implementing the System ISO 14001 Environmental Management in Sergipe sugarcane industries and pro- pose a waste management plan. The methodology was characterized as descriptive and exploratory, through field research and interview. The implementation of the proposed management plan in these industries will allow the appropriate management of waste, contributing to environmental preservation.

\section{KEYWORDS}

Agribusiness. Environmental Management. ISO 14001.

\section{RESUMEN}

La actividad de azúcar y etanol está afectando el medio ambiente, ya sea por el alto consumo de recursos naturales y la generación de residuos, por lo que este sector necesita adoptar iniciativas para minimizar estos impactos. Para fomentar estas actitudes se han establecido normas de gestión medioambiental que tengan por objetivo el establecimiento de directrices para la gestión eficaz de las actividades económicas, tales como la certificación ISO 14001 de Gestión Ambiental en las industrias de la caña de azúcar Sergipe y proponer un plan de gestión de residuos. La metodo- logía se caracteriza por ser descriptivo y exploratorio, a través de la investigación de campo y la entrevista. La implementación del plan de manejo propuesto en estas industrias permitirá la adecuada gestión de los residuos, lo que contribuye a la preservación del medio ambiente.

\section{PALABRAS CLAVE}

La agroindustria. La gestión ambiental. ISO 14001. 


\section{INTRODUÇ̄̃̃O}

A agroindústria, de maneira geral, pode ser definida, nas palavras de Belisário (1998), como qualquer atividade econômica que agregue valor a produtos provenientes de explorações agrícolas, pecuárias e florestais. Dentre as agroindústrias, a da cana-de-açúcar é um dos principais segmentos desse ramo. Para Piacente (2005), a agroindústria sucroalcooleira é uma atividade complexa, pois envolve um conjunto que é composto de um setor agrícola e outro setor estritamente industrial, muitas vezes, dividido em duas partes: fábrica de açúcar e destilaria de álcool.

A atividade de beneficiamento da cana-de-açúcar sempre obteve um espaço considerável para a economia brasileira. De acordo com o IEL/NC e SEBRAE (2012) a produção e o beneficiamento dessa matéria-prima constituíram elementos essenciais para o fortalecimento da economia nacional durante o ciclo da cana (séc. XVI e XVII). Atualmente o Brasil, segundo dados do Ministério da Agricultura, Pecuária e Abastecimento (MAPA) possui um total de 432 agroindústrias sucroalcooleiras (MAPA, 2011).

O sistema agroindustrial da cana-de-açúcar gera divisas para o Brasil por meio da produção, principalmente, do açúcar, do álcool anidro (aditivo da gasolina) e do álcool hidratado. Isso é devido a fatores como as excelentes perspectivas do comércio interno e internacional para estes produtos, o aumento do consumo do álcool hidratado em função do crescimento no número de modelos de automóveis flex-fuel (movidos a gasolina e álcool) e a crescente demanda por álcool anidro devido à necessidade dos países em reduzir a emissão de $\mathrm{CO}_{2}$.

O beneficiamento da cana destina-se a obter, também, outros produtos, como aguardente, rapadura e melaço. É matéria-prima para a produção de cosméticos, plásticos biodegradáveis, ração animal, entre outros subprodutos, que representam uma fonte alternativa de renda para as agroindústrias.
Em Sergipe, a produção de cana começou a desenvolver-se no século XVIII, sendo destacada a região do Vale do Cotinguiba. É importante salientar que a cana-de-açúcar em terras sergipanas nunca alcançou o nível de importância adquirido em outros estados nordestinos, como Alagoas e Pernambuco. A partir de pequenos engenhos movidos à tração animal, numerosos em todas as regiões úmidas do Estado, a produção canavieira foi se aperfeiçoando. Atualmente, o beneficiamento de cana em Sergipe concentra-se, principalmente, nas usinas localizadas nas cidades de Laranjeiras, Capela, Nossa Senhora das Dores e Japoatã.

Este setor da indústria está inserido no contexto de degradação do meio ambiente e, por isso, deve adotar medidas para minimização dos seus impactos ambientais. 0 processo industrial nas usinas de cana provoca um grande consumo de recursos naturais, a poluição atmosférica, contaminação do solo e dos corpos hídricos.

Tratando da questão dos resíduos na produção sucroalcooleira, a vinhaça, o principal resíduo líquido gerado na usina, é altamente poluidora. De acordo com Almeida e Santo (2007), o despejo da vinhaça nos cursos d'água causa odores e contribui para o agravamento de endemias como a malária, a amebíase e a esquistossomose. Além disso, a sua carga orgânica provoca a proliferação de microorganismos que esgotam o oxigênio dissolvido na água, destruindo a flora e a fauna aquáticas e dificultando o aproveitamento dos mananciais contaminados como fonte de abastecimento de água potável.

Os resíduos sólidos como bagaço, torta-filtro, levedura seca, óleo fúsil, também provocam degradação ambiental. Esse problema pode ser resolvido por meio do reaproveitamento destes resíduos como subprodutos da cana-de-açúcar. 
A partir da ideia de sustentabilidade é possível adotar atitudes ambientalmente aceitáveis e socialmente justas que possibilitarão o contínuo desenvolvimento econômico desse segmento, aliando a preservação do meio ambiente e responsabilidade social. A gestão ambiental é uma ferramenta imprescindível para atingir esses objetivos.

O Sistema de Gestão Ambiental da ISO 14001 é uma ferramenta de gestão com o intuito de ajudar aos setores da economia a transformarem suas atividades em menos agressoras do meio ambiente. Para isso estabelece ações para atingir esses objetivos, garantindo a sua continuidade.

A ABNT NBR ISO 14001 foi elaborada no Comitê Brasileiro de Gestão Ambiental (ABNT/CB-38), pela Comissão de Estudo de Gestão Ambiental (CE38:001.01). Esta norma equivale a ISO 14001: 2004. Tem por objetivo prover as organizações de elementos de um Sistema de Gestão Ambiental para auxiliar as empresas a alcançar seus objetivos ambientais e econômicos (ABNT NBR ISO 14001, 2004).

Essa norma não quer estabelecer padrões fixos ou requisitos absolutos de desempenho ambiental, apenas exige que as atividades estejam em conformidades com os requisitos legais. Por isso, ela pode ser aplicada em qualquer organização que deseje implantar um SGA. Também poderá ser implantada em apenas uma unidade operacional ou em atividades específicas, como no caso a gestão dos resíduos. A norma ISO 14001(2004) estabelece algumas etapas para implantação do Sistema de Gestão Ambiental (SGA): planejamento; implementação e operação; verificação e análise da administração.

Na visão de Robles (2006), o SGA melhora a imagem institucional da empresa, que poderá utilizar o marketing verde, obtendo vantagem competitiva no mercado global, amplamente disputado, onde os clientes, internos e externos, das organizações estão cada vez mais exigentes e conscientes em relação à preservação ambiental.
Para as agroindústrias canavieiras a implantação do Sistema de Gestão Ambiental, baseado na norma da NBR ISO 14001(2004) trará benefícios econômicos, ambientais e sociais para este setor. Uma vez que além da preservação do meio ambiente, ainda é possível obter ganhos econômicos por meio da redução consumo de recursos naturais e do valor agregado dado aos resíduos que são reaproveitados.

A implantação de um SGA da ISO 14001 nas usinas de cana em Sergipe permite conciliar o desenvolvimento econômico com a preservação do meio ambiente. Esse estudo objetivou analisar o interesse dessas agroindústrias canavieiras com relação à implantação do Sistema de Gestão Ambiental da ISO 14001 e elaborou um plano de gestão dos resíduos para essas usinas, considerando as exigências da legislação ambiental e a norma ISO 14001.

\section{METODOLOGIA}

\subsection{CARACTERIZAÇ̃̃̃ DA ÁREA DE ESTUDO}

0 estudo foi realizado em todas as agroindústrias sucroalcooleiras de Sergipe:

1. Usina São José do Pinheiro de Açúcar e Álcool Ltda, Laranjeiras/SE, produz de açúcar e álcool.

2. Usina Agroindustrial Campo Lindo Ltda, Nossa Sra. das Dores, produz de álcool.

3. Usina Termo Elétrica Iolando Leite, Capela/SE, produz de álcool e aguardente.

4. Usina Junco Novo Ltda, Capela/SE, produz álcool e aguardente.

5. Agroindustrial Capela Capela/SE, produz de álcool e aguardente. 
6. Unidade Industrial da Companhia Brasileira de Açúcar e Álcool, Japoatã/SE, produtora de álcool hidratado e anidro.

\subsection{PROCEDIMENTOS METODOLÓGICOS}

Para que o objetivo principal do trabalho apresentado fosse atingido, foi realizada uma pesquisa descritiva, baseada em estudo de caso. Essa alternativa foi escolhida devido à necessidade de identificar as principais ações realizadas pela agroindústria canavieira selecionada em relação a seus mais importantes resíduos.

Quanto aos meios, tratou-se de uma pesquisa bibliográfica, documental e de campo. Bibliográfica, porque para a fundamentação teórico-metodológica do trabalho foi realizada investigação sobre os seguintes assuntos: desenvolvimento sustentável, histórico da atividade canavieira no Brasil e Sergipe, os impactos ambientais decorrentes das atividades da agroindústria da cana, a gestão dos resíduos gerados em suas atividades e Norma Ambiental ISO 14001.

A investigação foi também documental, porque se valeu de documentos internos do Instituto Brasileiro de Geografia e Estatística (IBGE), da Empresa Brasileira de Pesquisa Agropecuária (Embrapa), e trabalhos acadêmicos. A pesquisa foi de campo, porque coletou e analisou dados pertencentes às agroindústrias canavieiras, utilizando o instrumento de entrevista semiestruturada e visita in loco para obter estas informações.

Quanto à natureza, entende-se que é uma pesquisa aplicada, pois que gera conhecimentos para aplicação prática, dirigidos à solução de problemas específicos. Em relação ao formulário para levantamento de dados para a realização do diagnóstico da gestão dos resíduos da agroindústria selecionada como estudo de caso, este foi elaborado com questões objetivas e em aberto.

Inicialmente foi realizado um contato telefônico com as Usinas, nesse contato foi introduzida a temática da pesquisa a ser realizada e cogitou-se a possibilidade deste a participar de uma entrevista semiestruturada.

Durante visita de campo em todas as usinas pesquisadas, buscou-se conhecer o processamento da matéria-prima para a produção e o que é feito com os resíduos, também foi realizada uma entrevista com o gestor responsável, utilizando como apoio um formulário com perguntas objetivas e subjetivas. Após essa etapa foi elaborado um plano de gestão para os resíduos baseado na ISO 14001.

\section{ANÁLISE E DISCUSSÃO DOS RESULTADOS}

Um dos objetivos da pesquisa é analisar o interesse das agroindústrias canavieiras com relação à implantação do Sistema de Gestão Ambiental da ISO 14001, visando o desenvolvimento sustentável. Para atingir tal finalidade, as entrevistas com os gestores das usinas foram fundamentais para entender qual a visão das agroindústrias com relação a essa Certificação ambiental da ISO.

Na fase inicial da entrevista com relação a essa temática foram abordadas perguntas sobre a implantação do Sistema de Gestão Ambiental baseado na ISO 14001. A primeira pergunta deste bloco consistiu em saber se a agroindústria entrevistada tem interesse em implantar ou já está em fase deimplantação de um Sistema de Gestão Ambiental.

Das seis empresas visitadas, apenas uma usina (17\%) respondeu afirmativamente ao questionamento sobre a implantação do SGA. Esta indústria é a mais tradicional do estado como também a de maior porte. Segundo o entrevistado algumas ações já tem sido implementadas como a finalidade de atingir esse interesse. Ela é a única dentre as entrevistadas que possui um profissional especializado (engenheiro ambiental) responsável pelo setor de meio ambiente. 
Cinco usinas, ou seja, 83\% do total do Estado, não esboçaram interesse na imediata implantação do Sistema de Gestão Ambiental, mas demonstraram interesse em futuramente adotarem este sistema como também maior conformidade com a legislação ambiental. As usinas que, no momento, não esboçaram o desejo de implantar o SGA apresentaram como principais justificativas as seguintes respostas:

- Estão procurando aos poucos adequarem-se as exigências ambientais;

- Enfrentam dificuldades porque falta interesse da alta gestão;

- As usinas por serem recentes ou estarem em processo de reestruturação possuem outras prioridades no momento como, por exemplo, investimentos em tecnologia para modernização da parte industrial, laboratórios, mas que o Sistema de Gestão Ambiental é uma meta futura, visto que o mercado e os órgãos financiadores cobram o compromisso ambiental das usinas, bem como produtos que não agridam o meio ambiente.

Diante do exposto, essa pesquisa observou que a gestão ambiental ainda não é uma prioridade para a maioria das usinas no Estado. Falta comprometimento com as questões ambientais. Talvez porque ainda não se tenha uma visão da importância que essas ações possam aumentar a rentabilidade do negócio, além de contribuir para a conquista de outros mercados consumidores.

Além disso, o órgão ambiental fiscalizador dessas atividades precisa estar mais atuante neste segmento econômico. Ainda sobre o Sistema de Gestão Ambiental, a entrevista com a usina que demonstrou interesse em implantar um SGA, demonstrou que os principais motivadores para a implantação do SGA são: aspectos relacionados à redução de custos, melhoria da imagem da empresa, cobrança dos órgãos ambientais e das instituições financiadores desse segmento industrial.
Ficou evidente, durante a entrevista, que dentre os objetivos principais que levam a usina a tornar suas práticas sustentáveis são, prioritariamente, às pressões dos agentes financiadores e de clientes e evitar penalidades por parte dos órgãos ambientais. Outro fator que dificulta a implantação da gestão ambiental é o desconhecimento, por parte da alta direção, da importância sustentabilidade das atividades da agroindústria.

Sobre as ações (investimentos) para a implementaçãode um SGA, tanto relacionados à parte física como de recursos humanos, a pesquisa apresenta os seguintes resultados: os investimentos de recursos físicos não demonstraram índices satisfatórios, pois a maioria dos itens sobre controle direto da parte agrícola e industrial estão em níveis baixos de satisfação. Já os investimentos em recursos humanos evidenciaram alguns resultados positivos como a contratação de profissional qualificado, a busca de auxílio de consultorias na área, o programa de coleta seletiva e algumas ações de educação ambiental.

Isso revela que a usina tem tomado algumas iniciativas para a gestão ambiental. Entretanto, é imprescindível que essas ações tenham uma continuidade e que outros pontos problemáticos passem a ser relevantes.

A implantação do SGA no setor sucroalcooleira é de fundamental importância para a sustentabilidade desse segmento. Diante disso, essa pesquisa, após análise da situação atual, propôs um plano de gestão dos resíduos gerados no beneficiamento da cana, baseado no SGA da Norma ISO 14001.

\subsection{PLANO DE MANEJO DOS RESÍDUOS DO SETOR INDUSTRIAL DE BENEFICIAMENTO DA CANA, BASEADO NO SISTEMA DE GESTÃO AMBIENTAL DA ISO 14001}

O desafio do setor agroindustrial da cana-de-açúcar em Sergipe é conciliar o seu desenvolvimento econômico com a preservação do meio ambiente. A proposta deste trabalho foi elaborar um plano de gestão desses resíduos baseado na norma ISO 14001. 
A proposta deste plano de gerenciamento foi sugerir melhorias e mudanças no manejo dos resíduos, com o intuito de melhor aproveitá-los, visando conciliar a conservação do meio ambiente e o desenvolvimento industrial. 0 plano de gestão é necessário visto que irá sistematizar as atividades de aproveitamento dos resíduos para que elas ocorram de forma eficiente e contínua.

Diante disso, esse plano de gestão dos resíduos tem a intenção de contribuir para que o setor sucroalcooleiro, em Sergipe, adote uma postura de aliado das questões ambientais, deixando de ser apenas exploradores dos seus recursos. Para a elaboração do plano foram estudadas formas de reaproveitamento dos resíduos da indústria da cana, presentes na literatura, que melhor se adaptem a realidade local, como também seguindo os padrões sugeridos pela certificação ambiental. Além disso, utilizou-se a experiência observada em outra usina que já possui a ISO 14001.

O Plano de Gestão Ambiental é uma ferramenta de gestão muito importante para que o setor canavieiro, em Sergipe, possa engajar-se nas questões relacionadas à preservação do meio ambiente. Esse plano poderá ser implantado em todas as atividades desenvolvidas pelas agroindústrias ou, em parte delas, sendo que o seu objetivo final é a certificação ambiental ISO 14001.

\section{Objetivos:}

- Desenvolvimento sustentável das agroindústrias canavieiras sergipanas;

- Preservação do meio ambiente;

- Cumprimento da legislação ambiental.

\section{Metas:}

- Reduzir os impactos ambientais das atividades canavieiras em Sergipe;
- Conceder destinação adequada a todos os resíduos gerados nas usinas;

- Posteriormente obter a Certificação Ambiental ISO 14001.

\section{Benefícios:}

\section{Econômicos:}

- Redução de custos com matéria-prima e pagamento de penalidades ambientais;

- Maior credibilidade com os agentes financiadores e mercado consumidor.

\section{Ambientais:}

- Redução de Impactos Ambientais das atividades canavieiras.

\section{Sociais:}

- Melhoria da relação das usinas com a comunidade local;

- Marketing verde.

\subsubsection{PROCEDIMENTOS ESTABELECIDOS NA ISO 14001 PLANEJAR, EXECUTAR, VERIFICAR E AGIR.}

\section{$\left.1^{\circ}\right)$ Planejamento:}

- Compromisso da alta direção;

- Seleção e designação formal de um coordenador ambiental;

- Formação de um Comitê de coordenação;

- Treinamento dos gestores, diretores e supervisores; 
- Definição dos Aspectos e Impactos ambientais e sua significância;

- Estabelecer a Política Ambiental da empresa.

\section{$\left.2^{\circ}\right)$ Executar:}

- Definição das ações ambientais;

- Documentação;

- Comunicação e Conscientização de todos os funcionários;

- Implantação Formal do Plano de gestão Ambiental.

\section{$\left.3^{\circ}\right)$ Verificar:}

- Monitoramento;

- Auditoria Interna;

- Ações Preventivas e Ações Corretivas;

- Análise pela administração.

\section{$\left.4^{\circ}\right)$ Agir:}

- Programa de Ação Contínua.

Quadro 1 - Ações para o desenvolvimento sustentável

\section{AÇÕES PARA O DESENVOLVIMENTO} SUSTENTÁVEL

- Projeto de monitoramento, proteção e recuperação de rios e nascentes que abastecem a usina.

- Programa de educação ambiental.

- Co-geração de energia através de biomassa (bagaço).

- Coleta seletiva e destinação adequada dos resíduos sólidos.
- Redução do consumo de água e utilização da água no processo industrial em circuito fechado.

- Tratamento dos efluentes líquidos da indústria.

- Aproveitamento da vinhaça e das águas residuarias para fertirrigação, obedecendo à legislação ambiental específica.

- Reaproveitamento da torta-filtro e a cinza do bagaço para adubação.

- Utilização de lavador de gases e controle das emissões atmosféricas.

- Participação em projetos de preservação ambiental da comunidade local.

Fonte: Adaptado do Sistema de Gestão Ambiental da Usina Coruripe, 2010 (COSTA, 2010).

Quadro 2 - Soluções sustentáveis para os Resíduos

\section{SOLUÇÕES SUSTENTÁVEIS PARA OS RESÍDUOS}

\begin{tabular}{|l|l|}
\multicolumn{1}{|c|}{ RESÍDUO } & \multicolumn{1}{c|}{ SOLUção } \\
\hline $\begin{array}{l}\text { Bagaço de } \\
\text { cana }\end{array}$ & $\begin{array}{l}\text { Co-geração de energia, ração } \\
\text { animal, produção de papel } \\
\text { reciclado, briquete e aglomerados } \\
\text { (indústria de móveis). }\end{array}$ \\
\hline Vinhaça & $\begin{array}{l}\text { Fertirrigação com controle da } \\
\text { lâmina de aplicação (norma } \\
\text { técnica p4.231/2006- cetesb) } .\end{array}$ \\
\hline Torta - filtro & Compostagem. \\
\hline $\begin{array}{l}\text { Águas } \\
\text { residuarias }\end{array}$ & $\begin{array}{l}\text { Reaproveitamento no processo } \\
\text { em circuito fechado; estação de } \\
\text { tratamento ou irrigação. }\end{array}$ \\
\hline Óleo fúsel & Venda para indústria química. \\
\hline $\begin{array}{l}\text { Efluente com } \\
\text { produtos } \\
\text { químicos }\end{array}$ & $\begin{array}{l}\text { Destinação aos postos de coleta } \\
\text { desse tipo de material. }\end{array}$ \\
\hline $\begin{array}{l}\text { Cinza do } \\
\text { bagaço }\end{array}$ & $\begin{array}{l}\text { Adubação ou para a indústria de } \\
\text { cimento } .\end{array}$ \\
\hline
\end{tabular}




\begin{tabular}{|l|l|}
\hline $\begin{array}{l}\text { Resíduos } \\
\text { oleosos }\end{array}$ & $\begin{array}{l}\text { Venda para indústria de } \\
\text { reaproveitamento desse material. }\end{array}$ \\
\hline $\begin{array}{l}\text { Sucatas de } \\
\text { metal }\end{array}$ & Coleta seletiva/reciclagem. \\
\hline Papel/papelão & Coleta seletiva/reciclagem. \\
\hline $\begin{array}{l}\text { Plásticos e } \\
\text { bombonas }\end{array}$ & Coleta seletiva/reciclagem. \\
\hline $\begin{array}{l}\text { Lixo } \\
\text { doméstico }\end{array}$ & Aterro sanitário. \\
\hline $\begin{array}{l}\text { Pneus/ } \\
\text { borrachas }\end{array}$ & $\begin{array}{l}\text { Venda para indústria de } \\
\text { reaproveitamento desse material. }\end{array}$ \\
\hline $\begin{array}{l}\text { Gases } \\
\text { poluentes }\end{array}$ & $\begin{array}{l}\text { Investimento em equipamentos } \\
\text { e tecnologias para redução das } \\
\text { emissões. }\end{array}$ \\
\hline $\begin{array}{l}\text { Esgotos } \\
\text { sanitários }\end{array}$ & $\begin{array}{l}\text { Estação de tratamento de } \\
\text { efluentes. }\end{array}$ \\
\hline
\end{tabular}

Fonte: Adaptado do Sistema de Gestão Ambiental da Usina Coruripe, 2010 (COSTA, 2010).

Todas as fases de planejamento, execução e verificação são imprescindíveis para o Plano de Gestão Ambiental. Entretanto, isolada, nenhuma destas etapas será suficiente para garantir o sucesso da Gestão Ambiental, por isso é necessário assegurar a sua continuidade.

\section{CONCLUSÕES}

A cadeia sucroenergética tem mostrado seu potencial em trabalhar de forma sustentável, respeitando os limites do meio ambiente sem comprometer sua capacidade econômica. A gestão dos resíduos, utilizando como base a Norma Ambiental ISO 14001 é uma das ferramentas importante para a redução dos impactos ambientais do beneficiamento da cana-de-açúcar.

O plano de gestão dos resíduos da indústria da cana-de-açúcar, elaborado nesta pesquisa, auxilia- rá as agroindústrias canavieiras sergipanas a manejarem de forma sustentável os seus resíduos. Ele apresenta algumas soluções para reduzir os impactos ambientais decorrentes da geração e descarte inadequado dos resíduos da cana. É evidente que este plano não pretende limitar ou impor formas de aproveitamento. Contudo, tem o objetivo de sugerir algumas alternativas de manejo que poderão ser aperfeiçoadas, tendo em vista o equilíbrio entre as atividades agroindustriais canavieiras e a preservação do meio ambiente.

A temática da gestão ambiental na indústria canavieira é uma área muito abrangente para o conhecimento científico. Por isso, essa pesquisa deixa como sugestão o desenvolvimento de estudos futuros voltados para outras formas de aproveitamento dos resíduos da cana, além daquelas já existentes na literatura, o estudo com vinhaça, bagaço, torta filtro, óleo fúsil, levedura seca, bem como, a realização de estudos sobre maneiras de recuperação de áreas degradadas devido ao cultivo da cana, biorremediação de solos e águas contaminados pelo uso excessivo da vinhaça para fertirrigação.

Além disso, podem ser ampliados projetos na área de educação ambiental, marketing, novas tecnologias e gestão no âmbito das atividades econômicas canavieiras, contribuindo para a eliminação e/ou minimização dos impactos ambientais inerentes a atividade da indústria canavieira.

\section{REFERÊNCIAS}

ABNT NBR ISO 14001. 2004. Sistema de gestão

ambiental. Disponível em:<http://www.unematnet.br/downloads/nbr-iso-14001-2004.pdf>. Acesso em: out. 2014.

ALMEIDA, L. T. de; SANTO, Z. N. E. Etanol: impactos sócio-ambientais de uma commodity em ascensão. In: VII Encontro da Sociedade Brasileira de Economia 
Ecológica, 2007, Fortaleza/CE. Anais eletrônicos do VII Encontro da Sociedade Brasileira de Economia Ecológica, 2007. Disponível em: <http// www. ecoeco.org.br>. Acesso em: out. 2014.

BELISÁRIO, J. S. A agroindústria familiar. In: Simpósio Agricultura capixaba no limiar do século XXI - ameaças e oportunidades, 1998, Vitória/ES.

Anais do Simpósio Agricultura capixaba no limiar do século XXI - ameaças e oportunidades, v.2, 1998, p. 171.

CERQUEIRA, J. P. Sistemas de gestão integrados. Rio de Janeiro/RJ: Qualitymark, 2006. 500p.

IEL/NC; SEBRAE. 0 novo ciclo da cana: estudo sobre a competitividade do sistema agroindustrial da canade-açúcar e prospecção de novos empreendimentos. Brasília: IEL/NC; SEBRAE, 2012. 337p.
MATOS, A. T. de. Tratamento de resíduos

agroindustriais. Curso sobre tratamento de resíduos agroindustriais, UFV, 2005.

\section{MAPA - Ministério da Agricultura, Pecuária e} abastecimento - Disponível em: http://<www. agricultura.gov.br>. Acesso em: maio 2011.

\section{PIACENTE, F. J. Agroindústria canavieira e o sistema} de gestão ambiental: o caso das usinas localizadas nas bacias hidrográficas dos rios Piracicaba, Capivari e Jundiaí. 2005. 177f. Dissertação (Mestrado do Programa de Pós-Graduação em Desenvolvimento Econômico da UNICAMP) - Campinas/SP: UNICAMP. Disponível em: <http://<www.cori.unicamp.br>. Acesso em: nov. 2011.

ROBLES, A. Jr., BONELLI, V. V. Gestão da qualidade e do meio ambiente: enfoque econômico, financeiro e patrimonial. São Paulo/SP: Atlas, 2006. 112p. sidade Federal de Sergipe (UFS), São Cristóvão - SE; Tecnóloga em Saneamento Ambiental. E-mail: izaclaudiasantana@yahoo.com.br

2. Doutoranda em Desenvolvimento e Meio Ambiente - Programa de Pós-Graduação em Desenvolvimento e Meio Ambiente (Prodema), da Universidade Federal de Sergipe (UFS), São Cristóvão - SE; Bacharel em Administração. E-mail: icbandrade@yahoo.com.br

3. Prof. Dr. do Departamento de Engenharia Química e do Programa de Pós-Graduação em Desenvolvimento e Meio Ambiente (Prodema) da Universidade Federal de Sergipe (UFS), São Cristóvão - SE. E-mail: souza@ufs.br

4. Prof. Dr. do Departamento de Engenharia Agronômica - DEA/Programa de Pós-Graduação em Meio Ambiente e Desenvolvimento (Prodema) da Universidade Federal de Sergipe (UFS), São Cristóvão - SE. E-mail: gregoAceito em: 20 de Janeiro de 2015 